\title{
Orbital Myositis
}

National Cancer Institute

\section{Source}

National Cancer Institute. Orbital Myositis. NCI Thesaurus. Code C117296.

A rare form of myositis that affects only the orbital muscles. 